\title{
Synthesis and Magnetorheology Study of Iron Oxide and Iron Cobalt Oxide Suspensions
}

\author{
Syang-Peng Rwei, ${ }^{1}$ Lee Yi Wang, ${ }^{2}$ and Po-Wen Yang ${ }^{1}$ \\ ${ }^{1}$ Institute of Organic and Polymeric Materials, National Taipei University of Technology, No. 1, Section 3, \\ Chung-Hsiao E. Road, Taipei 10648, Taiwan \\ ${ }^{2}$ Center Condensed Matter Science, National Taiwan University, Taipei, Taiwan
}

Correspondence should be addressed to Syang-Peng Rwei; f10714@ntut.edu.tw

Received 9 March 2013; Revised 25 May 2013; Accepted 27 May 2013

Academic Editor: Anjan Barman

Copyright (C) 2013 Syang-Peng Rwei et al. This is an open access article distributed under the Creative Commons Attribution License, which permits unrestricted use, distribution, and reproduction in any medium, provided the original work is properly cited.

\begin{abstract}
This study investigates the magnetorheology (MR) of polydimethylsiloxane (PDMS) that contains magnetic powders of various compositions, shapes, and concentrations. Two magnetic powders, $\mathrm{Fe}_{3} \mathrm{O}_{4}$ and $\mathrm{CoFe}_{2} \mathrm{O}_{4}$, were synthesized. TEM images reveal that a powder of spherical particles was obtained at high temperature. A powder with nonspherical star shape was synthesized at low temperature. A rheological test confirmed a typical Bingham behavior for all the MR fluids prepared in this study. Experimental results demonstrated that the cobalt ferrite exhibited a more superior yield stress than the ferrite compound. A magnetic powder of larger particles was found to have higher yield stress. Moreover, the spherical particles yielded a higher yield stress than the star-shaped particles. The "saturated magnetic strength" increased with the loading of the magnetic powder. Finally, the results demonstrate that $12 \mathrm{wt} \% \mathrm{CoFe}_{2} \mathrm{O}_{4}$ nanopowder $(10 \mathrm{~nm})$ dispersed in the PDMS liquid exhibited a large range of yield stresses $(0$ to $644 \mathrm{~Pa})$.
\end{abstract}

\section{Introduction}

A magnetorheological (MR) fluid can be rapidly transformed from a Newtonian fluid-like structure to a solid-like structure with viscoelastic-plastic yielding by applying a magnetic field [1-7]. Rabinow [8] discovered this phenomenon in 1948. Since then, various metal or ceramic powders with magnetic characteristics have been dispersed in nonmagnetic carrier liquids [9], such as oil or aqueous liquids, in the preparation of MR fluids. The smart damper design [10] is currently the most advanced application of MR suspensions. It releases energy using a magnetorheological dashpot and uses electric power to align magnetic nanoparticles that are suspended in liquid with a magnetic warp. The particles are orientated almost perpendicular to the direction of fluid motion (Figure 1). Accordingly, the flow is blocked and the viscosity is thus increased. Regardless of the magnitude of a shock, the energy dissipation always remains optimal in the smart damper because the viscosity of the suspension can be adjusted.
Among all the methods to produce the magnetic nanoparticles [11-13], the thermal decomposition method was the most common one in a lab scale and was therefore selected in this work. This study investigates the magnetic fluids, with a view to form magnetic nanoparticles of different shapes and sizes under the control of chemosynthesis [14-18] and then to mix them with PDMS to make magnetic fluid with various solid loadings. MR tests are then performed. The most common MR fluid consists of particles on a micronscale, normally 5-200 $\mu \mathrm{m}$ in size. The micron-scale particles are too weak to be stabilized by the Brownian motion, and, using which, the reproducibility of MR characterization is difficult to achieve. Accordingly, the sedimentation of particles remains a critical problem to solve in relation to most designed MR fluids-even those that involve added surfactants. Nanoparticles, however, can be easily stabilized in a liquid with the aid of Brownian motion and the repulsive effect from the surfactant. A special synthetic approach was followed in this study to produce nanoscale particles in a manner that eliminates the sedimentation problem. 


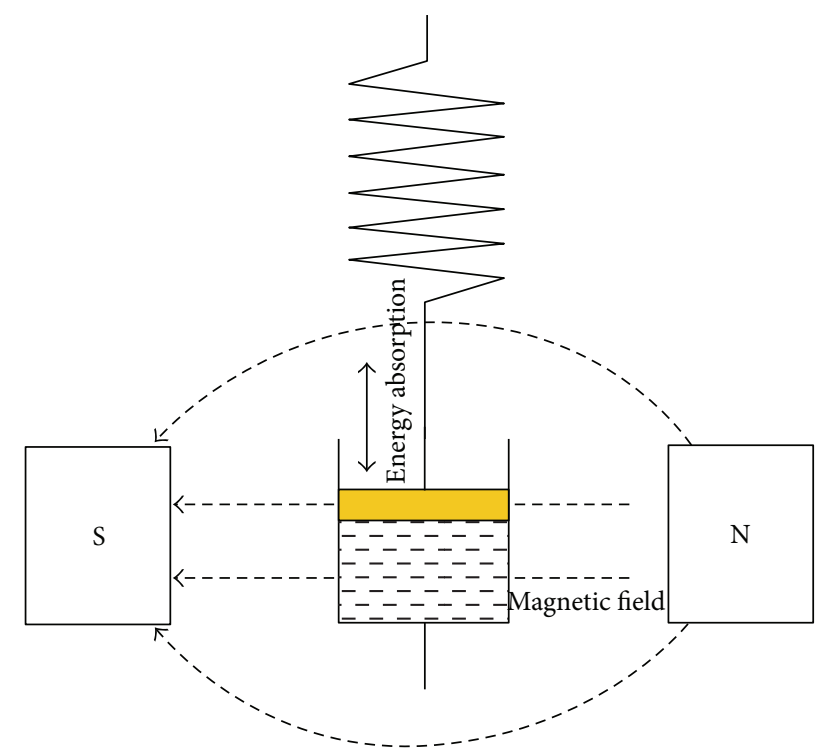

FIGURE 1: Schematic diagram of magnetorheological damper [19].

\section{Experimental}

2.1. Preparation of Iron Oxide $\left(\mathrm{Fe}_{3} \mathrm{O}_{4}\right)$ Nanoparticles. $\mathrm{FeCl}_{3} \cdot \mathrm{H}_{2} \mathrm{O} \quad(10.8 \mathrm{~g}, 40 \mathrm{mmol})$, sodium oleate $(36.5 \mathrm{~g}$, $120 \mathrm{mmol})$, distilled water $(60 \mathrm{~mL})$, ethanol $(80 \mathrm{~mL})$, and hexane $(140 \mathrm{~mL})$ were put in a $500 \mathrm{~mL}$ three-neck flask and stirred under nitrogen for one hour to dissolve them completely. Then, the flask was mounted onto a condensing system and heated to $70^{\circ} \mathrm{C}$ at a heating rate of $3.3^{\circ} \mathrm{C} / \mathrm{min}$ in the nitrogen environment. This temperature was maintained for 4.5 hours and three extractions were performed after the reaction using distilled water $(60 \mathrm{~mL})$. The iron-oleate complex (1) with a black-brown appearance was obtained. A rotary concentrator was then used to remove the solvent.

Product (1) (9.00 g, $10 \mathrm{mmol})$, oleic acid (1.73 g, $6 \mathrm{mmol})$ and tri-n-octylamine $(30.00 \mathrm{~g})$ were put in a $500 \mathrm{~mL}$ threeneck flask. A magnet was added and stirred in a nitrogen environment for 40 minutes to mix the contents uniformly. The condensing system, in the nitrogen environment, was set up to 300 or $366^{\circ} \mathrm{C}$ at a heating rate of $3.3^{\circ} \mathrm{C} / \mathrm{min}$. A black solution was obtained after reaction for 30 minutes. The ethanol was used to separate out the black solid, namely, the $\mathrm{Fe}_{3} \mathrm{O}_{4}$ product. Finally, the $\mathrm{Fe}_{3} \mathrm{O}_{4}$ was purified using hexane to remove the organic substance on its surface (Figure 2).

2.2. Preparation of Iron Cobalt Oxide $\left(\mathrm{CoFe}_{2} \mathrm{O}_{4}\right)$ Nanoparticles. The cobalt ferrite nanoparticles have been prepared using the method developed by Hyeon as follows [20]. Iron (III) acetylacetonate $(0.71 \mathrm{~g}, 2 \mathrm{mmol})$, cobalt (II) acetylacetonate $(0.26 \mathrm{~g}, 1 \mathrm{mmol})$, and 1,2-tetradecanediol $(2.56 \mathrm{~g}$, $10 \mathrm{mmol}$ ) were put in a $500 \mathrm{~mL}$ three-neck flask. Nitrogen deoxidized phenyl ether $(20 \mathrm{~mL})$, oleic acid $(1.73 \mathrm{~g}, 6 \mathrm{mmol})$, and oleyamine $(2.00 \mathrm{~g}, 6 \mathrm{mmol})$ were then added and stirred in a nitrogen environment for one hour to ensure uniform mixing. The condensing system, in the nitrogen environment, was set up to $200^{\circ} \mathrm{C}$ at a rate of $3.3^{\circ} \mathrm{C} / \mathrm{min}$ and maintained for 30 minutes; the system was then heated to $265^{\circ} \mathrm{C}$ at a heating rate of $3.3^{\circ} \mathrm{C} / \mathrm{min}$ and maintained for 30 minutes. Alternatively, the condenser was heated to $300^{\circ} \mathrm{C}$ and maintained for one hour after reaction at $200^{\circ} \mathrm{C}$ for two hours. A black solution was yielded after the reaction is complete and ethanol was used to separate out the black solid. The black solid thus obtained is the product $\mathrm{CoFe}_{2} \mathrm{O}_{4}$. The $\mathrm{CoFe}_{2} \mathrm{O}_{4}$ was purified using hexane to remove the organic substance on its surface (Figure 3). All of the chemicals used were supplied by ACROS Chemicals and used without further purification.

2.3. Preparation of Magnetic Fluid. The magnetic material $0.2 \mathrm{~g}$ was blended with $1.5 \mathrm{~mL}$ polydimethylsiloxane (PDMS, viscosity $100 \mathrm{cp}$ ) and stirred uniformly. The content was poured into the lower plate of rheometer (Anton Paar Physica MCR301 MRD). Then, the upper plate was lowered to maintain the spacing between the plates at $0.1 \mathrm{~cm}$. The temperature of the rheometer was kept at $25^{\circ} \mathrm{C}$. The yield stress of the object was measured under various magnetic strength. The samples were prepared in the following orders: (1) $\mathrm{Fe}_{3} \mathrm{O}_{4}\left(300^{\circ} \mathrm{C}\right)$, (2) $\mathrm{Fe}_{3} \mathrm{O}_{4}\left(366^{\circ} \mathrm{C}\right)$, (3) $\mathrm{CoFe}_{2} \mathrm{O}_{4}\left(265^{\circ} \mathrm{C}\right)$, and (4) $\mathrm{CoFe}_{2} \mathrm{O}_{4}\left(300^{\circ} \mathrm{C}\right)$.

2.4. Principle of Magnetorheology. Figures 4(a) to 4(d) present the basic principle of magnetorheology. When a magnetic fluid is placed in a magnetic field, magnetic nanoparticles are temporarily in a network state, as shown in Figures 4(b) to 4(c). The purpose of shear test is to determine the critical shear stress, also known as the yield stress, which disrupts the network state (Figure 4(d)). A larger yield stress indicates that the tested MR fluid exhibits a stronger MR effect.

The pure PDMS fluid that was used herein is a Newtonian fluid. An MR fluid, in contrast, exhibits Bingham character in a magnetic field. Such a Bingham fluid [19] has a so-called yield stress $\left(\tau_{0}\right)$. The MR fluid must overcome this threshold for the onset of fluidity in a magnetic field. Equation (1) defines "apparent viscosity" $\left(\mu_{a}\right)$, taking into account the yield stress in viscosity calculation.

$$
\begin{gathered}
\tau=\tau_{0}+\mu_{0} \dot{\gamma}, \\
\mu_{a}=\frac{\tau}{\dot{\gamma}}=\frac{\tau_{0}}{\dot{\gamma}}+\mu_{0} .
\end{gathered}
$$

In (1), $\tau$ denotes the shear stress; $\tau_{0}$ denotes the yield stress; $\mu_{0}$ denotes the quasi-Newtonian viscosity; $\dot{\gamma}$ represents the shear rate, which is the gradient of the velocity against the vertical displacement, and $\mu_{a}$ represents the apparent viscosity, which is the ratio of the measured shear stress to the given shear rate.

For a fixed shear rate, a larger yield stress corresponds to a higher apparent viscosity. The magnetic field is adjusted by varying the electric current, and the targeted apparent viscosity is thereby obtained.

\section{Results and Discussion}

Figure 5(a) presents the wide-angle X-ray diffraction pattern of $\mathrm{Fe}_{3} \mathrm{O}_{4}$ particles that were synthesized in this work. All of 


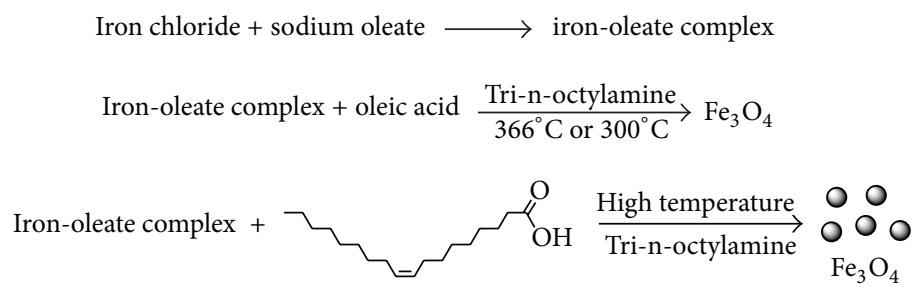

Figure 2: Scheme of $\mathrm{Fe}_{3} \mathrm{O}_{4}$ nanoparticle Synthesis.

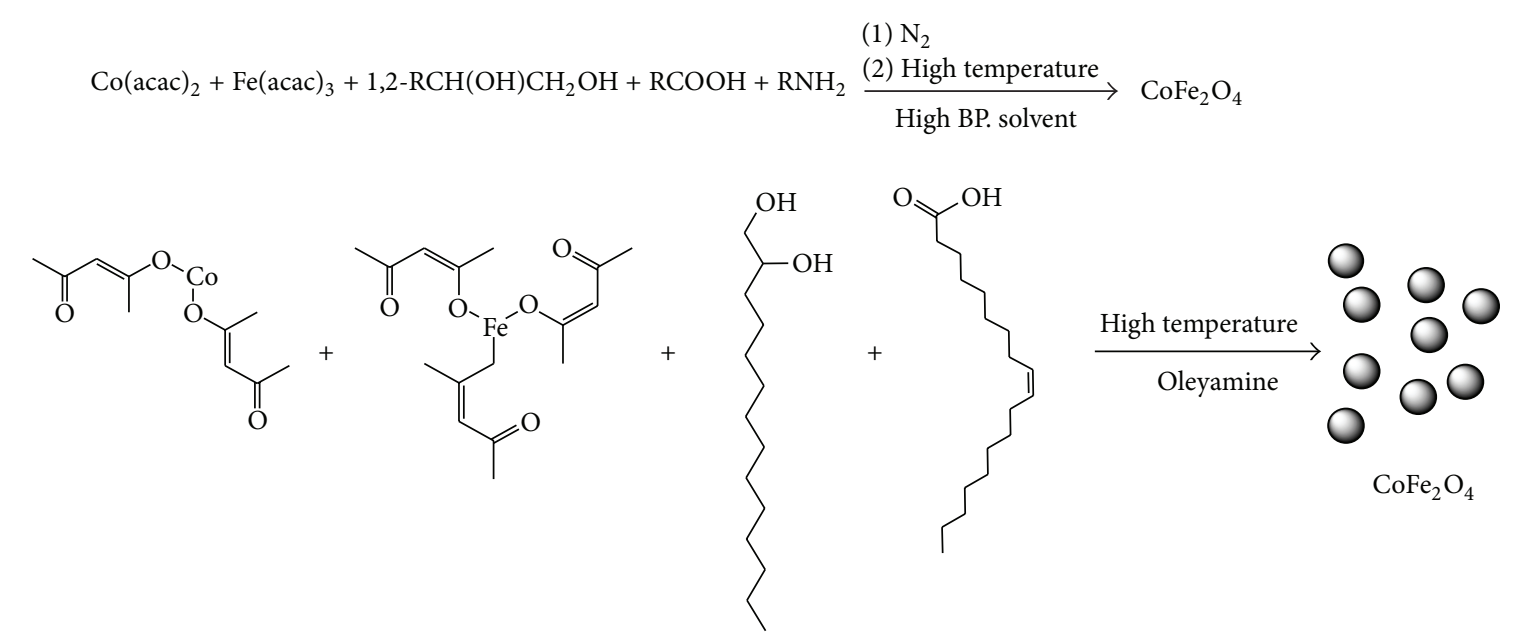

Figure 3: Preparation of iron cobalt oxide $\left(\mathrm{CoFe}_{2} \mathrm{O}_{4}\right)$ nanoparticles.

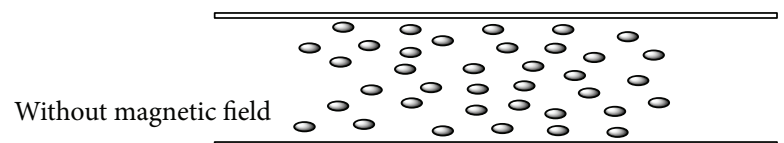

(a)

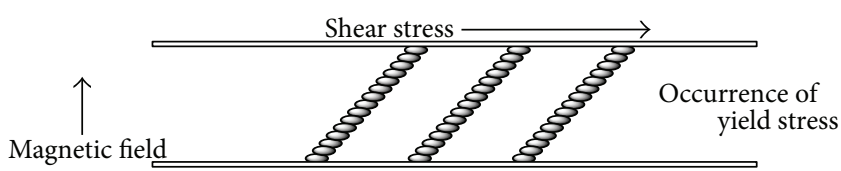

(c)

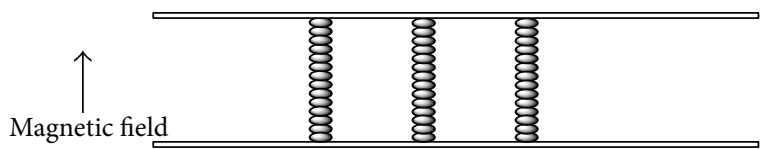

(b)

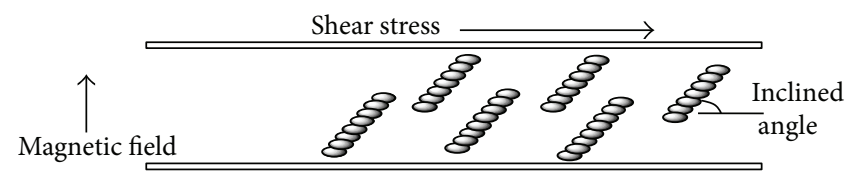

(d)

FIGURE 4: Schematic diagram of yield stress.

the characteristic peaks of the crystal (30.1 (200), 35.4 (311), 37.0 (222), 43.1 (400), 53.4 (422), 56.9 (511), 62.5 (440)) are similar to other scholars' results $[21,22]$, proving that the synthesized particles are granular $\mathrm{Fe}_{3} \mathrm{O}_{4}$ crystals. The wideangle X-ray diffraction pattern of $\mathrm{CoFe}_{2} \mathrm{O}_{4}$ particles that were synthesized in this work was shown in Figure 5(b). All of the characteristic peaks (18.1 (111), 30.1 (220), 35.7 (311), 37.0 (222), 43.1 (400), 53.4 (422), 57.0 (511), 62.5 (440)) of the crystal are similar to other scholars' results [23-25], indicating that the synthesized particles are granular $\mathrm{CoFe}_{2} \mathrm{O}_{4}$ crystals.

Figures 6(a) and 6(b) are TEM photos of $\mathrm{Fe}_{3} \mathrm{O}_{4}$ particles that were synthesized at $366^{\circ} \mathrm{C}$ and $300^{\circ} \mathrm{C}$, respectively. They reveal that the particles formed at $300^{\circ} \mathrm{C}$ are star shaped; the longest diagonal distance between two apexes is $80 \mathrm{~nm}$, and the internal diameter of the particles is around $40 \mathrm{~nm}$. In contrast, regular, spherical particles (30 $\mathrm{nm}$ in diameter) are obtained at $366^{\circ} \mathrm{C}$, suggesting that a high temperature yields round and uniform particles, and a low temperature yields nonspherical particles, even with multi-acute angles.

Crystallization is usually divided into "nucleation" and "growth" stages. Low temperature favors nucleation but is disadvantageous to growth, whereas high temperature disfavors nucleation but favors growth. The reactant diffusion rate is low at low temperature. The crystal nucleus is unlikely to grow uniformly to form a 3-D symmetrical sphere; in contrast, particles with polygonal shape are synthesized. The convex 


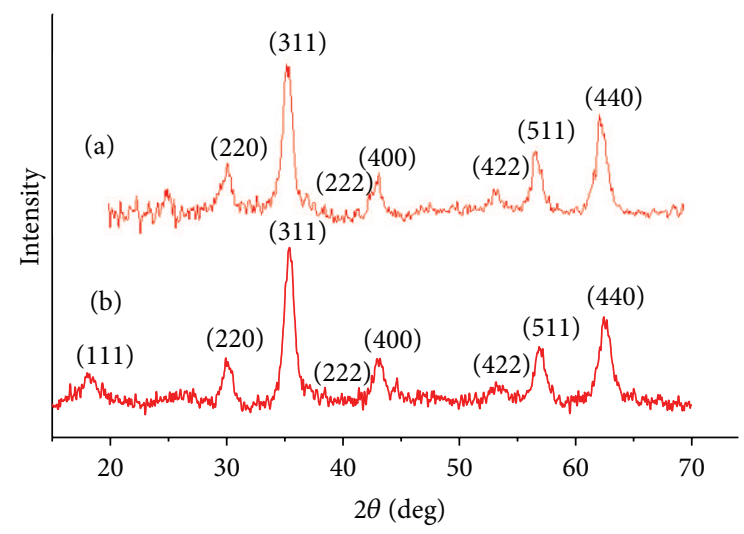

Figure 5: X-ray diffraction pattern of (a) $\mathrm{Fe}_{3} \mathrm{O}_{4}$ and (b) $\mathrm{CoFe}_{2} \mathrm{O}_{4}$.

surfaces of a polygonal particle can more easily capture a new $\mathrm{Fe}_{3} \mathrm{O}_{4}$ ionic particle than can do the spherical surfaces, so the crystal keeps growing along the convexity and forms several arms. Therefore, star-shaped particles with multiacute angles are formed. However, the diffusion rate is high at high temperature, and the crystal nuclei are uniform, so numerous new $\mathrm{Fe}_{3} \mathrm{O}_{4}$ ionic particles are stratified on the surface of each nucleus simultaneously. The crystallization time is too short to allow any nucleus to form a convexity, so round crystals uniformly grow instead. The formation of the star-shaped or polygonal nanoparticles was also observed by other scholars $[26,27]$, and similar growth mechanism was proposed.

Figures 6(c) and 6(d) are the TEM images of $\mathrm{CoFe}_{2} \mathrm{O}_{4}$ particles that were synthesized at $265^{\circ} \mathrm{C}$ and $300^{\circ} \mathrm{C}$, respectively. Particles that were synthesized at high temperature were spherical with a relatively uniform diameter of approximately $10 \mathrm{~nm}$. Particles synthesized at low temperature, however, are nonspherical and have sizes of $3 \sim 5 \mathrm{~nm}$. The difference between the shapes of $\mathrm{CoFe}_{2} \mathrm{O}_{4}$ particles can be explained similarly to the mechanism of formation of the $\mathrm{Fe}_{3} \mathrm{O}_{4}$ particles mentioned previously; a high temperature promotes the formation of round particles because the rate of the diffusion of the ionic particles is high enough to make the suspension contain a homogenous ionic-particle distribution at high temperature. At higher temperatures, nucleation and growth may not be easily separated. The homogeneity of the crystallization process is better and can thus yield a more spherical particle with a larger diameter. The relationship between synthesis temperature and the shape of $\mathrm{CoFe}_{2} \mathrm{O}_{4}$ and $\mathrm{Fe}_{3} \mathrm{O}_{4}$ particles is shown in Table 1. Notably, the dependence of temperature on particle size and shape is only valid for the "thermal decomposition method" used herein. Similar result was also reported by other scholars [28].

Figure 7 presents the MR result of $\mathrm{CoFe}_{2} \mathrm{O}_{4}$ (synthesized at $300^{\circ} \mathrm{C}$ ) dispersed in PDMS (12 wt\%). The MR fluid clearly changed from a Newtonian fluid to a Bingham fluid when a magnetic field was applied. As the magnetic field increases, the yield stress $\left(\tau_{0}\right)$ increases, and the quasi-Newtonian viscosity $\left(\mu_{0}\right)$ of the fluid increases. Table 2 summarizes the results from Figure 7 . Table 2 demonstrates that the yield stress, defined as the extrapolated stress at zero shear rate,
TABLE 1: Various shapes and sizes of nanoparticles synthesized at different temperatures.

\begin{tabular}{lccc}
\hline Particle type & $\begin{array}{c}\text { Synthesis } \\
\text { temperature } \\
\left({ }^{\circ} \mathrm{C}\right)\end{array}$ & Shape & Diameter $(\mathrm{nm})$ \\
\hline $\mathrm{Fe}_{3} \mathrm{O}_{4}$ & 300 & Star & $40 \pm 6^{*}$ \\
$\mathrm{Fe}_{3} \mathrm{O}_{4}$ & 366 & Sphere & $30 \pm 2$ \\
$\mathrm{CoFe}_{2} \mathrm{O}_{4}$ & 265 & Sphere & $3 \pm 1$ \\
$\mathrm{CoFe}_{2} \mathrm{O}_{4}$ & 300 & Sphere & $10 \pm 3$ \\
\hline
\end{tabular}

${ }^{*}$ The mean value of the core-diameter of the star particles.

TABLE 2: The $\tau_{0 a}$ and $\mu_{0}$ of $\mathrm{CoFe}_{2} \mathrm{O}_{4} 12 \mathrm{wt} \%$ MR fluid under different magnetic strengths.

\begin{tabular}{lcc}
\hline Magnetic field strength (Gauss) & $\tau_{0 a}(\mathrm{~Pa})$ & $\mu_{0}(\mathrm{~Pa} \mathrm{~S})$ \\
\hline 0 & 0 & 0.5 \\
1400 & 296.8 & 0.9 \\
2800 & 404.3 & 1.2 \\
5800 & 511.5 & 1.4 \\
8600 & 576.7 & 1.5 \\
10000 & 644.3 & 1.6 \\
\hline
\end{tabular}

increases with the magnetic field. Accordingly, when the magnetic field increases, the magnitude of the yield stress, which is the range of deformation before fracture, increases, as demonstrated in Figure 4(c). If the line of magnetic nanoparticles is broken, then various dispersed particle groups advance in the original direction of the shear force and thus flow forward. However, the magnetic field causes the particle groups to follow an inclination that deviates from the direction of flow in the flow process. A larger deviation corresponds to greater resistance of the fluid and, therefore, a greater viscous stress. Therefore, quasi-Newtonian viscosity $\left(\mu_{0}\right)$ increases with magnetic force. In fact, the Bingham yield stress $\left(\tau_{0}\right)$ and quasi-Newtonian viscosity $\left(\mu_{0}\right)$ do not increase without limit. When the magnetic field continues to increase, the magnetic fluids eventually reach their own "saturated magnetic strength."

Figure 8 plots the relationship between yield stress $\left(\tau_{0}\right)$ and magnetic flux density $(\mathrm{G})$ for $\mathrm{Fe}_{3} \mathrm{O}_{4}\left(366^{\circ} \mathrm{C}\right)$ fluid at various concentrations. Evidently, the yield stress increases with the magnetic field. However, the saturated magnetic strength, which the yield stress does not further increase after the magnetic force is raised over, can be obtained for the $\mathrm{Fe}_{3} \mathrm{O}_{4}$ suspension at a low concentration. Figure 8 reveals that the saturated magnetic strengths of $3 \mathrm{wt} \%$ and $6 \mathrm{wt} \% \mathrm{Fe}_{3} \mathrm{O}_{4}$ fluids are $6000 \mathrm{G}$ and $8600 \mathrm{G}$, respectively. However, the saturation point of $12 \mathrm{wt} \% \mathrm{Fe}_{3} \mathrm{O}_{4}$ is far beyond the measurable range (10000 G) of the instrument, so it cannot be determined. In summary, Figure 8 demonstrated that the saturated magnetic strength increases with the particle concentrations.

Figure 9 plots the shear stress against shear rate for magnetic nanoparticles with different shape, size, and species. Figure 9 plots the effect of size on the MR behavior of $\mathrm{CoFe}_{2} \mathrm{O}_{4}$ particles of similar shapes (spherical or almost spherical). $\mathrm{CoFe}_{2} \mathrm{O}_{4}$ particles with a diameter of $10 \mathrm{~nm}$ have 


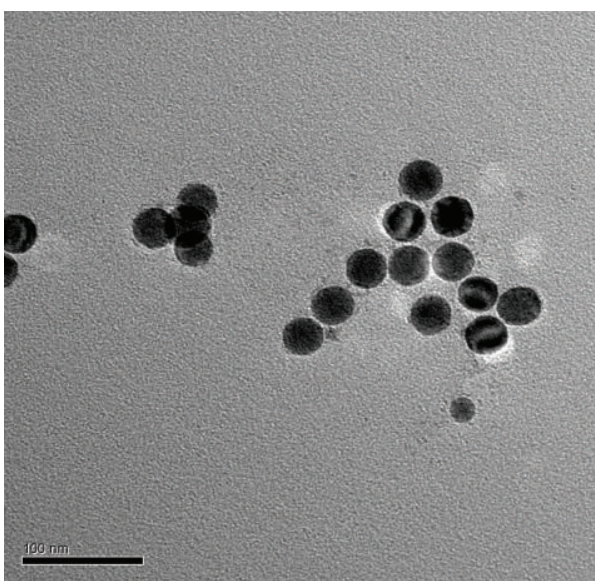

(a)

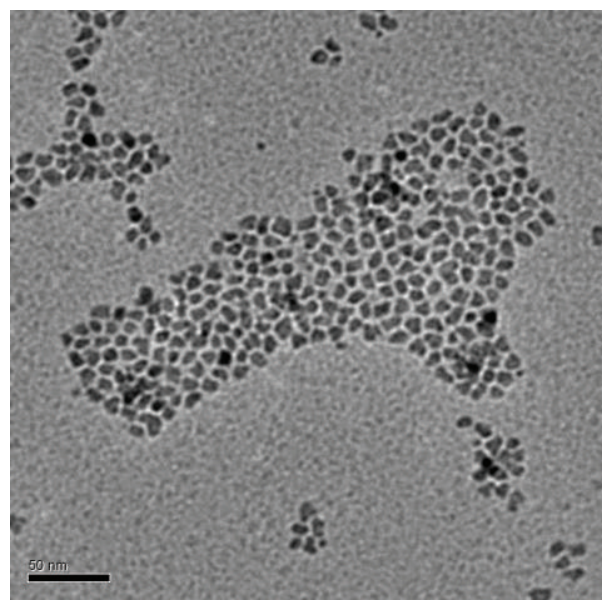

(c)

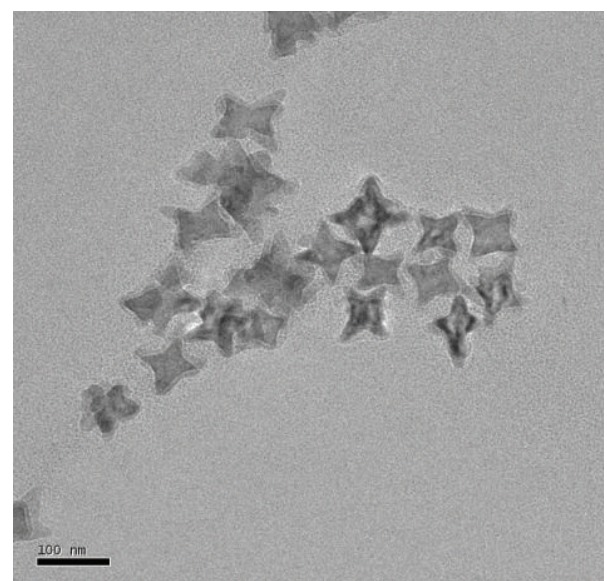

(b)

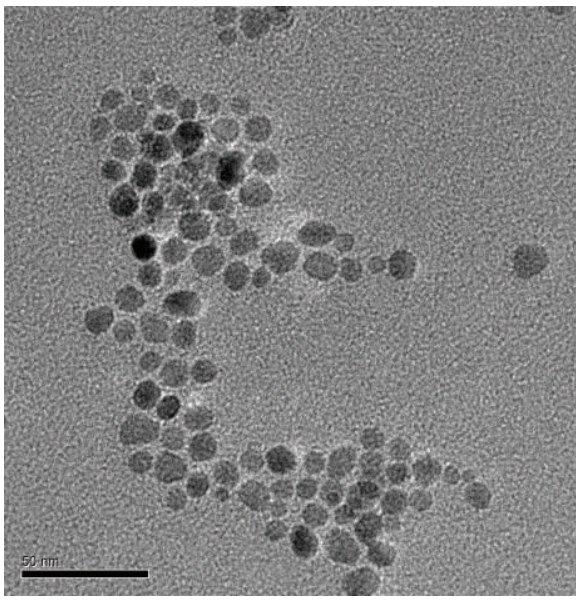

(d)

Figure 6: TEM photographs of (a) $\mathrm{Fe}_{3} \mathrm{O}_{4}$ particles synthesized at $366^{\circ} \mathrm{C}$, (b) $\mathrm{Fe}_{3} \mathrm{O}_{4}$ particles synthesized at $300^{\circ} \mathrm{C},(\mathrm{c}) \mathrm{CoFe}_{2} \mathrm{O}_{4}$ synthesizing particles at $265^{\circ} \mathrm{C}$, and (d) $\mathrm{CoFe}_{2} \mathrm{O}_{4}$ synthesizing particles at $300^{\circ} \mathrm{C}$.

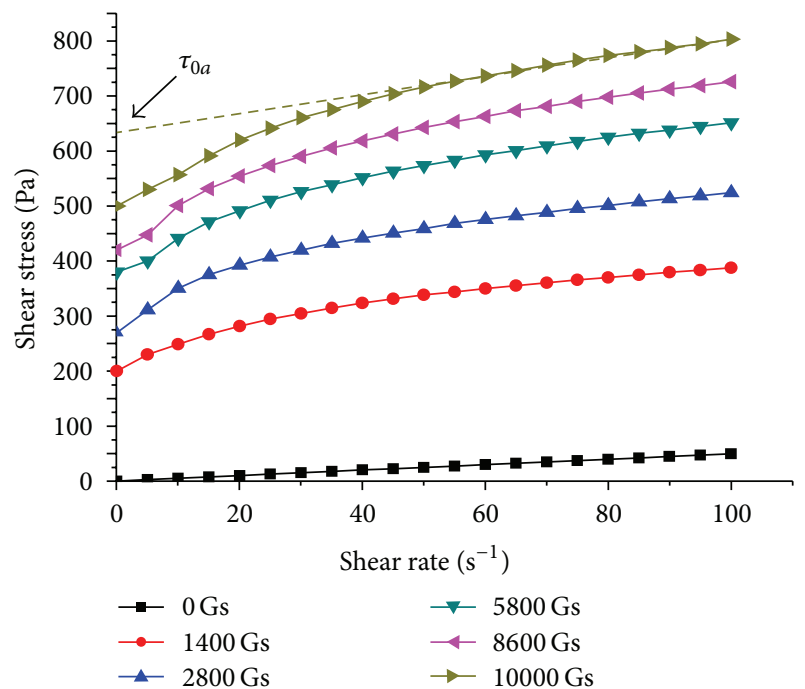

FIGURE 7: Shear stress is a function of shear rate for $\mathrm{CoFe}_{2} \mathrm{O}_{4}$ particles, synthesized at $300^{\circ} \mathrm{C}$, under various magnetic fields.

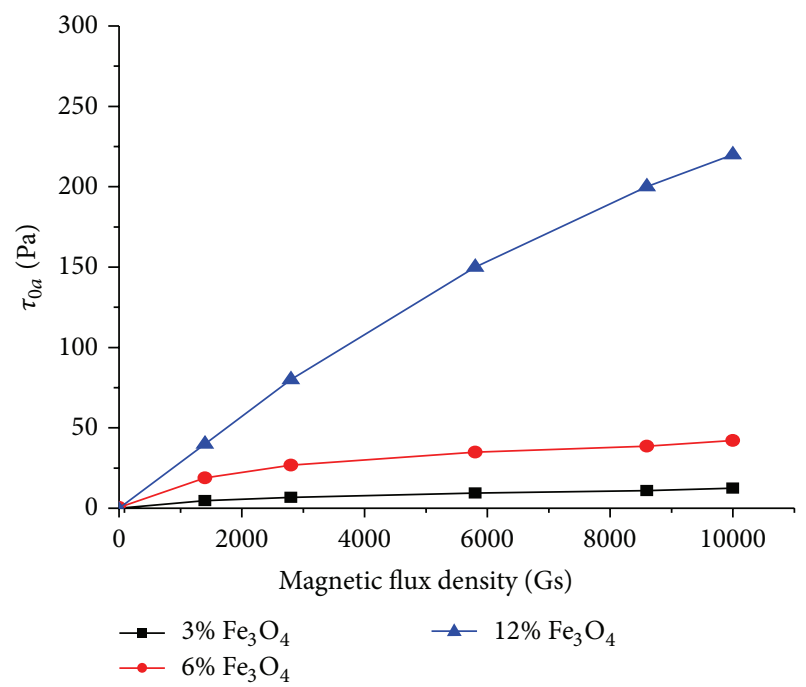

FIgURE 8: The yield stress of $\mathrm{Fe}_{3} \mathrm{O}_{4}$ fluid at different solid loading $\left(366^{\circ} \mathrm{C}\right)$ as a function of magnetic flux intensity (Gauss). 


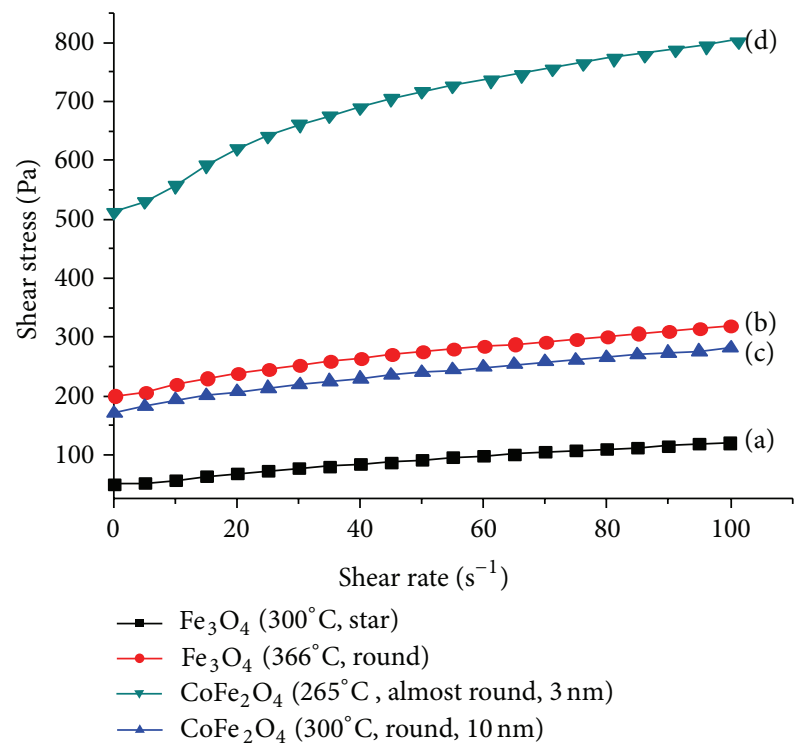

FIGURE 9: Shear stress against shear rate for various magnetic nanoparticles dispersed in silicone oil (10000 Gauss, $25^{\circ} \mathrm{C}, 12 \mathrm{wt} \%$ ).
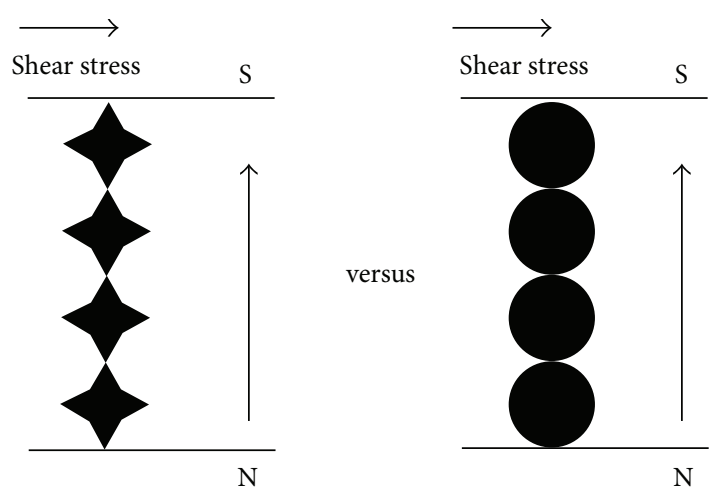

FIGURE 10: Effect of shear stress and magnetic force on star-shaped and round particles.

the best yield stress, $644 \mathrm{~Pa}$, and quasi-Newtonian viscosity, 1.6 Pa S. $\mathrm{CoFe}_{2} \mathrm{O}_{4}$ particles with a smaller diameter, $3 \mathrm{~nm}$, have a poor yield stress, which is only one third of that of the larger panicles, $188 \mathrm{~Pa}$. Theoretically, a larger particle has fewer connection points and is unlikely to be destroyed by shear stress. Therefore, it can exhibit a higher MR yield stress. Figure 9 demonstrates that the yield stress of the $\mathrm{CoFe}_{2} \mathrm{O}_{4}$ series clearly exceeds that of the $\mathrm{Fe}_{3} \mathrm{O}_{4}$ series, indicating that the magnetic strength of iron cobalt oxide exceeds that of iron oxide [29]. The incorporation of the Co cation in the Fe-O matrix greatly increases the magnetic anisotropy of the materials, resulting in higher coercivity. Ferromagnetic materials with high coercivity have permanent magnets which can sustain a harsh and complex hydrodynamic environment and yield a good MR behavior. The drawback of the particles with high coercivity is the problem of particle dispersion when the field is out [30,31]. How to prepare an MR fluid with high magnetic strength but low self-flocculation is a tough task for us in the future.

Figure 10 illustrates that a round particle of $\mathrm{Fe}_{3} \mathrm{O}_{4}$ has a higher yield stress than a star particle. The core diameter of the star particle $(40 \mathrm{~nm})$ exceeds the diameter of the round particle $(30 \mathrm{~nm})$. According to the results for ferrocobalt oxide, larger particles are associated with higher yield stress, but the experiment to which Figure 9 pertains yields the opposite result. The junction of the star-shaped particle may be the connection between two arms, and it is less stable than the connection of two round particles. Accordingly, this fragile joint is easy to be destroyed by a shear force, resulting in a reduced yield force.

\section{Conclusions}

$\mathrm{Fe}_{3} \mathrm{O}_{4}$ is likely to be synthesized at high temperature $\left(366^{\circ} \mathrm{C}\right)$ as round uniformly sized particles, and at low temperature $\left(300^{\circ} \mathrm{C}\right)$ as star-shaped particles. Based on the MR test results, we conclude the following.

(1) The yield stress of the $\mathrm{CoFe}_{2} \mathrm{O}_{4}$ fluid is three to ten times higher than that of $\mathrm{Fe}_{3} \mathrm{O}_{4}$ fluid at the same concentration.

(2) In an MR fluid of round $\mathrm{CoFe}_{2} \mathrm{O}_{4}$ particles larger particles produce higher yield stress.

(3) The yield stress of MR fluid with round particles exceeds that of such a fluid with star-shaped particles.

(4) In an MR test, the "saturated magnetic strength" increases with the particle concentration.

\section{Disclosure}

The MR fluids are prepared according to the method mentioned herein as a novel method. Although it still has long way to go for commercial application, its patents have been claimed and filed by the authors and the financial founder: NSC of Taiwan. There is no conflict of interests for any commercial application at present time or in the future.

\section{Acknowledgment}

The authors would like to thank the National Science Council of the Republic of China (NSC), Taiwan, for financially supporting this research under Contract no. NSC_98-2221-E027-003-MY3.

\section{References}

[1] I. Bica, "Influence of the transverse magnetic field intensity upon the electric resistance of the magnetorheological elastomer containing graphite microparticles," Materials Letters, vol. 63, no. 26, pp. 2230-2232, 2009.

[2] J. H. Kim, F. F. Fang, H. J. Choi, and Y. Seo, "Magnetic composites of conducting polyaniline/nano-sized magnetite and their magnetorheology," Materials Letters, vol. 62, no. 17-18, pp. 28972899, 2008. 
[3] W. H. Li, C. Lynam, J. Chen, B. Liu, X. Z. Zhang, and G. G. Wallace, "Magnetorheology of single-walled nanotube dispersions," Materials Letters, vol. 61, no. 14-15, pp. 3116-3118, 2007.

[4] C. C. Ekwebelam and H. See, "Using oscillatory shear to probe the effects of bidispersity in inverse ferrofluids," Korea Australia Rheology Journal, vol. 19, no. 1, pp. 35-42, 2007.

[5] H. Pu, F. Jiang, and Z. Yang, "Studies on preparation and chemical stability of reduced iron particles encapsulated with polysiloxane nano-films," Materials Letters, vol. 60, no. 1, pp. 94-97, 2006.

[6] W. H. Li and X. Z. Zhang, "The effect of friction on magnetorheological fluids," Korea Australia Rheology Journal, vol. 20, no. 2, pp. 45-50, 2008.

[7] S. P. Rwei, H. Y. Lee, S. D. Yoo, L. Y. Wang, and J. G. Lin, "Magnetorheological characteristics of aqueous suspensions that contain $\mathrm{Fe}_{3} \mathrm{O}_{4}$ nanoparticles," Colloid and Polymer Science, vol. 283, no. 11, pp. 1253-1258, 2005.

[8] J. Rabinow, "The magnetic fluid clutch," Transactions of the American Institute of Electrical Engineers, vol. 67, no. 2, pp. 13081315, 1948.

[9] I. Bica, "The influence of the magnetic field on the electrical magnetoresistance of magnetorheological suspensions," Journal of Magnetism and Magnetic Materials, vol. 299, no. 2, pp. 412418, 2006.

[10] R. Stanway, "Smart fluids: current and future developments," Materials Science and Technology, vol. 20, no. 8, pp. 931-939, 2004.

[11] S. Chakrabarti, S. K. Mandal, and S. Chaudhuri, "Cobalt doped $\gamma-\mathrm{Fe}_{2} \mathrm{O}_{3}$ nanoparticles: synthesis and magnetic properties," Nanotechnology, vol. 16, no. 4, pp. 506-511, 2005.

[12] S. K. Mandal, "Fluorescent magnetic emulsion droplets: potential material for multiplexed optical coding of biomolecules," Journal of Magnetism and Magnetic Materials, vol. 311, no. 1, pp. 88-91, 2007.

[13] S. K. Mandal, N. Lequeux, B. Rotenberg et al., "Encapsulation of magnetic and fluorescent nanoparticles in emulsion droplets," Langmuir, vol. 21, no. 9, pp. 4175-4179, 2005.

[14] H. R. Brand and H. Pleiner, "Origin of the slow wave in a magnetorheological slurry," Physical Review Letters, vol. 86, pp. 1385-1385, 2000.

[15] M. Liţă, N. C. Popa, C. Velescu, and L. N. Vékás, "Investigations of a magnetorheological fluid damper," IEEE Transactions on Magnetics, vol. 40, no. 2 I, pp. 469-472, 2004.

[16] H. Böse, "Viscoelastic properties of silicone-based magnetorheological elastomers," International Journal of Modern Physics B, vol. 21, no. 28-29, pp. 4790-4797, 2007.

[17] H. See, C. Joung, and C. Ekwebelam, "Dynamic behavior and yielding of field-responsive particulate suspensions," International Journal of Modern Physics B, vol. 21, no. 28-29, pp. 49454951, 2007.

[18] R. C. Bell, E. D. Miller, J. O. Karli, A. N. Vavreck, and D. T. Zimmerman, "Influence of particle shape on the properties of magnetorheological fluids," International Journal of Modern Physics B, vol. 21, no. 28-29, pp. 5018-5025, 2007.

[19] F. A. Morrison, Understanding Rheology, Guernsey, UK, 2001.

[20] T. Hyeon, Y. Chung, J. Park, S. S. Lee, Y.-W. Kim, and B. H. Park, "Synthesis of highly crystalline and monodisperse cobalt ferrite nanocrystals," Journal of Physical Chemistry B, vol. 106, no. 27, pp. 6831-6833, 2002.

[21] K. Hayashi, W. Sakamoto, and T. Yogo, "Magnetic and rheological properties of monodisperse $\mathrm{Fe}_{3} \mathrm{O}_{4}$ nanoparticle/organic hybrid," Journal of Magnetism and Magnetic Materials, vol. 321, no. 5, pp. 450-457, 2009.

[22] A. Kida, C. Yamamoto, M. Doi, H. Asano, and M. Matsui, "Magnetoresistance of trilayer films with $\mathrm{Fe}_{3} \mathrm{O}_{4}$," Journal of Magnetism and Magnetic Materials, vol. 272-276, no. 1, pp. e1559-e1561, 2004.

[23] M. M. Rashad, R. M. Mohamed, and H. El-Shall, "Magnetic properties of nanocrystalline Sm-substituted $\mathrm{CoFe}_{2} \mathrm{O}_{4}$ synthesized by citrate precursor method," Journal of Materials Processing Technology, vol. 198, no. 1-3, pp. 139-146, 2008.

[24] L. A. García Cerda and S. M. Montemayor, "Synthesis of $\mathrm{CoFe}_{2} \mathrm{O}_{4}$ nanoparticles embedded in a silica matrix by the citrate precursor technique," Journal of Magnetism and Magnetic Materials, vol. 294, no. 2, pp. e43-e46, 2005.

[25] D. Maity and D. C. Agrawal, "Synthesis of iron oxide nanoparticles under oxidizing environment and their stabilization in aqueous and non-aqueous media," Journal of Magnetism and Magnetic Materials, vol. 308, no. 1, pp. 46-55, 2007.

[26] C. L. Nehl, H. Liao, and J. H. Hafner, "Optical properties of starshaped gold nanoparticles," Nano Letters, vol. 6, no. 4, pp. 683688, 2006.

[27] C. Yang, J. Wu, and $\mathrm{Y}$. $\mathrm{Hou}$, " $\mathrm{Fe}_{3} \mathrm{O}_{4}$ nanostructures: synthesis, growth mechanism, properties and applications," Chemical Communications, vol. 47, no. 18, pp. 5130-5141, 2011.

[28] W. W. Yu, J. C. Falkner, C. T. Yavuz, and V. L. Colvin, "Synthesis of monodisperse iron oxide nanocrystals by thermal decomposition of iron carboxylate salts," Chemical Communications, vol. 10, no. 20, pp. 2306-2307, 2004.

[29] A. Hernando, I. Navarro, C. Prados, D. García, M. Vázquez, and J. Alonso, "Curie-temperature enhancement of ferromagnetic phases in nanoscale heterogeneous systems," Physical Review B, vol. 53, no. 13, pp. 8223-8226, 1996.

[30] S.-Y. Zhao, K. L. Don, W. K. Chang, G. C. Hyun, H. K. Young, and S. K. Young, "Synthesis of magnetic nanoparticles of $\mathrm{Fe}_{3} \mathrm{O}_{4}$ and $\mathrm{CoFe}_{2} \mathrm{O}_{4}$ and their surface modification by surfactant adsorption," Bulletin of the Korean Chemical Society, vol. 27, no. 2, pp. 237-242, 2006.

[31] S. Sun, H. Zeng, D. B. Robinson et al., "Monodisperse $\mathrm{MFe}_{2} \mathrm{O}_{4}$ $(\mathrm{M}=\mathrm{Fe}, \mathrm{Co}, \mathrm{Mn})$ Nanoparticles," Journal of the American Chemical Society, vol. 126, no. 1, pp. 273-279, 2004. 

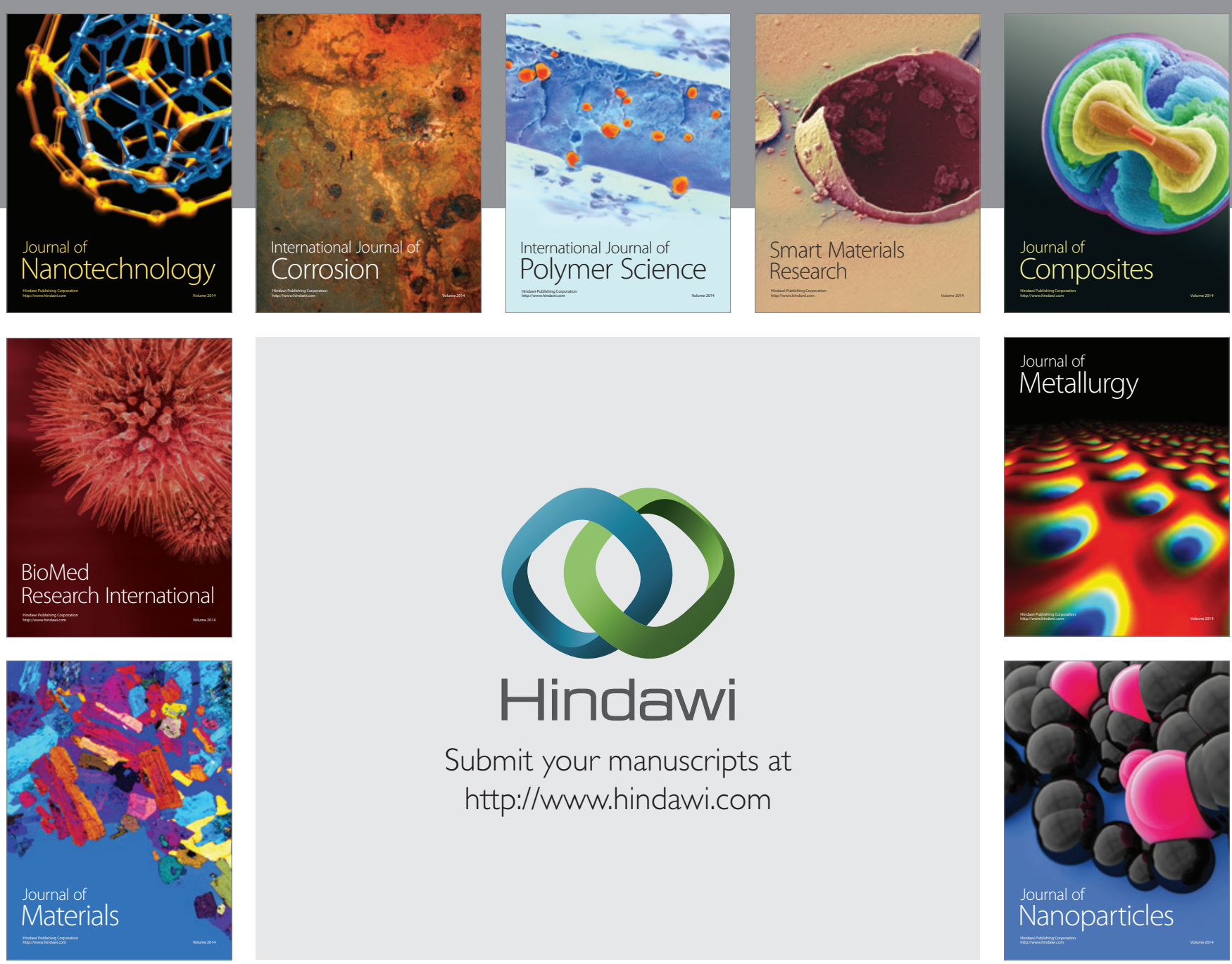

Submit your manuscripts at http://www.hindawi.com
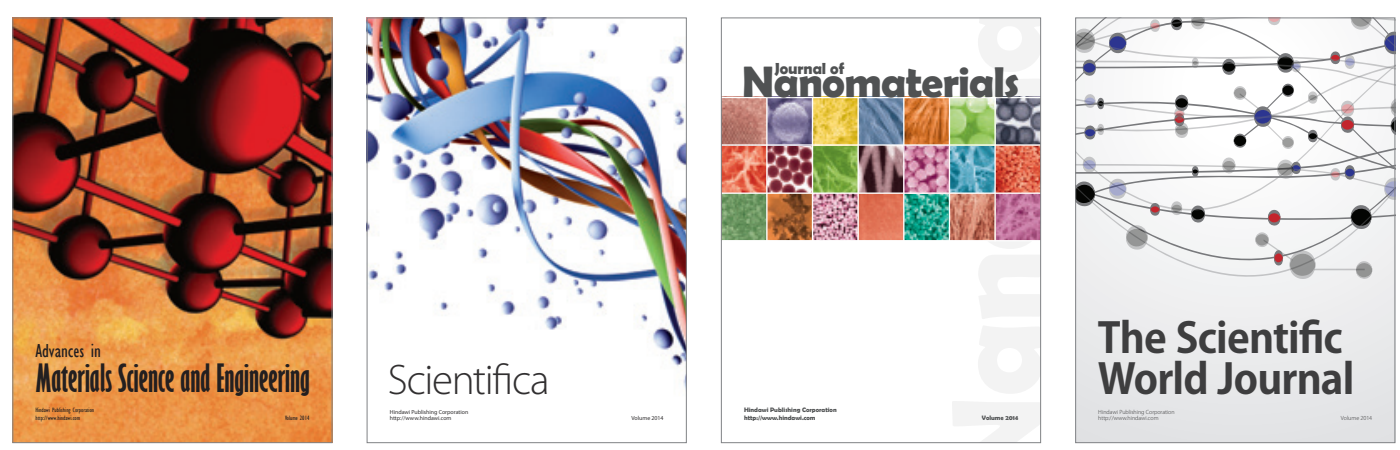

\section{The Scientific World Journal}
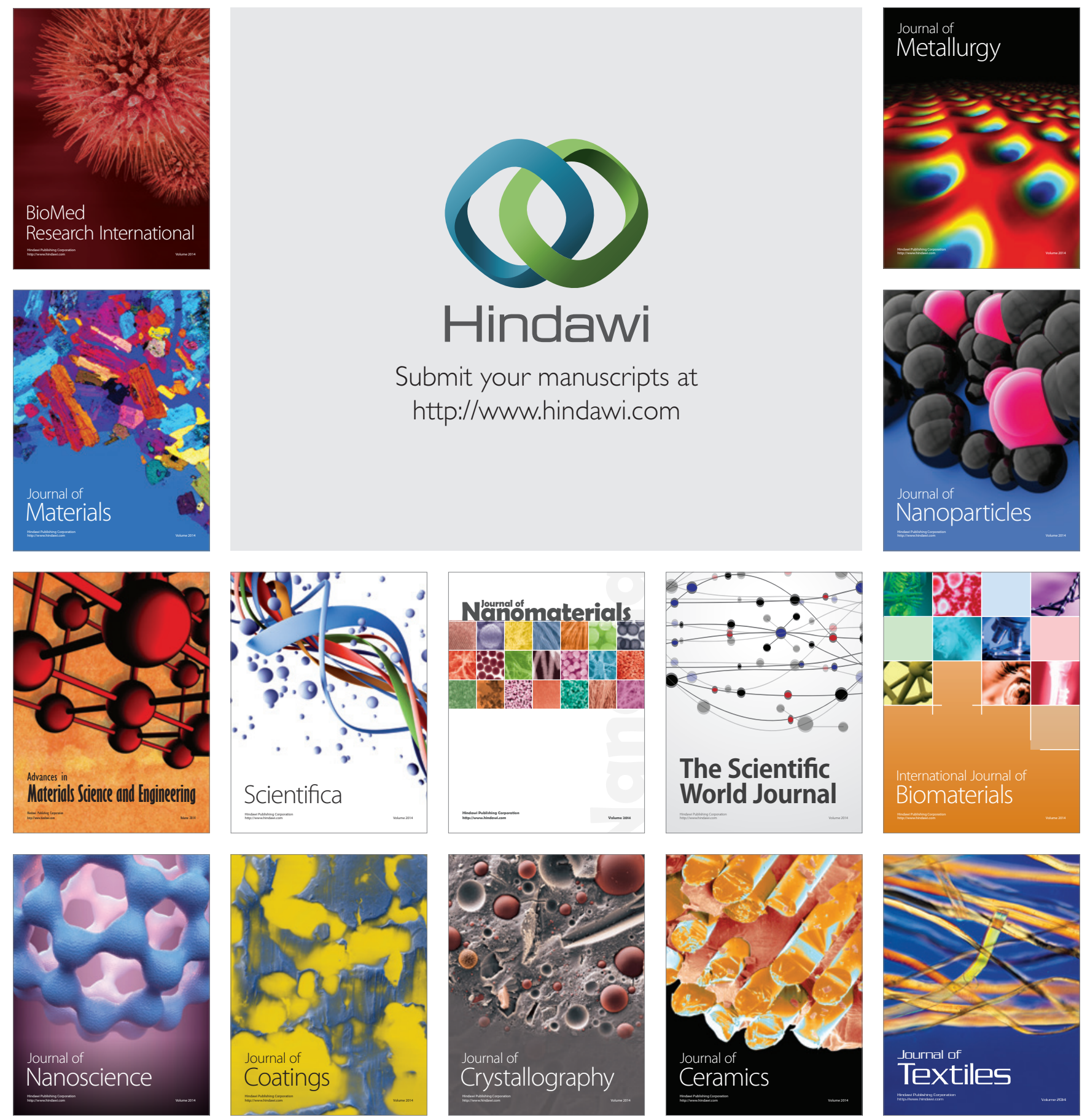